\title{
PENERAPAN TEKNOLOGI HEMAT AIR PADA BUDIDAYA TANAMAN SEMUSIM LAHAN KERING DI DESA BAUMATA TIMUR KABUPATEN KUPANG
}

\author{
Maria Klara Salli * M.Basri** \\ *Jurusan Manajemen Pertanian Lahan Kering, Politeknik Pertanian Negeri Kupang \\ Jl. Prof. Dr. Herman Yohanes - Lasiana - Kupang - Nusa Tenggara Timur \\ *Email : arie.salli@yahoo.com \\ **Email : mh_basri@yahoo.com
}

\begin{abstract}
Abstrak
Mitra 1 dan Mitra 2 adalah petani tanaman semusim lahan kering di Desa Baumata Timur Kecamatan Taebenu Kabupaten Kupang. Mitra 1 dan 2 merupakan petani pemula yang mulai usaha budidaya tanaman semusim satu tahun terakhir (2016-2017). Kenyataan di lapangan untuk musim menjelang kemarau dari 0,5 ha itu tidak semua ditanami karena kekurangan air. Mulsa plastik hitam perak sudah di gunakan kedua mitra namun masih sedikit karena kendala modal. Analisis usahatani belum dilakukan dengan baik, pencatatan usaha tani tidak lengkap. Permasalahan mitra adalah a).usaha tani tanaman sayuran mengalami kendala kekurangan air, b). petani terbatas dalam menentukan tanaman semusim yang akan di budidayakan, $c$ ). belum berkembangnya teknologi hemat air di tingkat petani karena keterbatasan pengetahuan dan modal dan d).mitra masih terbatas dalam pencatatan usaha tani nya sehingga analisis usaha tidak dilakukan dengan baik dan pasti.

Target luaran yang diharapkan terjadi pada kelompok mitra adalah mitra dapat melakukan teknologi pemulsaan menggunakan plastik hitam perak dengan irigasi drip, sehingga dapat efisien terhadap penggunaan air dan lahan yang dimanfaatkan lebih luas dari sebelumnya, mitra dapat melakukan teknik budidaya tanaman semusim dengan baik, mitra memiliki catatan usahataninya secara baik dan dapat melakukan analisis usaha sehingga mitra dengan pasti mengetahui untung rugi usahatani nya.

Metode yang dipakai dalam kegiatan PKM adalah metode ceramah (preaching method), metode diskusi (discussion method), on farm method (penerapan langsung di lahan petani), pendampingan, monitoring dan evaluasi pelaksanaan kegiatan.

Hasil kegiatan PKM yaitu Kegiatan PKM dapat terlaksana dengan baik, ditunjukkan dengan partisipasi mitra yang tinggi dan budidaya tanaman semusim berhasil dilakukan mitra.

Kegitan PKM ini dapat menyelesaikan permasalahan mitra yaitu mitra dapat menyelesaikan permasalahan kekurangan air yaitu dengan teknologi hemat air berupa pemulsaan dan irigasi drip, sehingga lebih banyak lahan yang tertanami, mitra dapat meningkatkan pengetahuan dan ketrampilan dalam budidaya tanaman semusim, dan mitra dapat melakukan pencatatan usahataninya dengan baik. Kegiatan PKM ini sangat bermanfaat bagi mitra, selain meningkatkan keterampilan mitra juga sebagai sumber pendapatan mitra.
\end{abstract}

Kata Kunci : Teknologi hemat air, budidaya, tanaman semusim, lahan kering

\section{PENDAHULUAN}

Desa Baumata Timur adalah salah satu desa yang ada di Kecamatan Taebenu kabupaten Kupang provinsi Nusa Tenggara Timur (NTT). Didominasi oleh lahan kering, kecamatan Taebenu yang mempunyai lahan kering seluas 5170 ha atau $94.2 \%$. Kondisi lahan seperti ini mempengaruhi model pertaniannya. Kendala teknis yang paling krusial pada lahan kering adalah air. Ketersediaan air untuk pengembangan lahan kering sepenuhnya bergantung pada curah hujan dan perilaku hujan sangat dinamik dan eratik. Secara kuantitatif, jumlah curah hujan per tahun sebetulnya cukup untuk menunjang produksi tanaman tetapi ketersediaannya mengumpul pada periode singkat yaitu Nopember atau Desember sampai Maret ((Lidjang, I.K. et al. 2003).
Budidaya tanaman pada umumnya dilakukan pada musim hujan yaitu petani menanam padi dan jagung sedangkan tanaman hortikultura biasanya di tanam pada musim kemarau apabila air mencukupi. Budidaya tanaman semusim dilakukan secara terbatas sesuai ketersediaan air yang ada. Di desa Baumata Timur ini terdapat dua orang petani mitra kegiatan program pengabdian masyarakat. Kegiatan pertaniannya meliputi budidaya tanaman semusim yaitu tanaman pangan dan tanaman hortikultura. Masing-masing petani memiliki luas lahan $\pm 0,5$ ha, dimana tidak semua lahan dapat ditanami seluruhnya karena kendala air. Air menjadi kendala utama dalam kegiatan budidaya tanaman. Kondisi lahan mitra dapat dilihat pada gambar 1. 


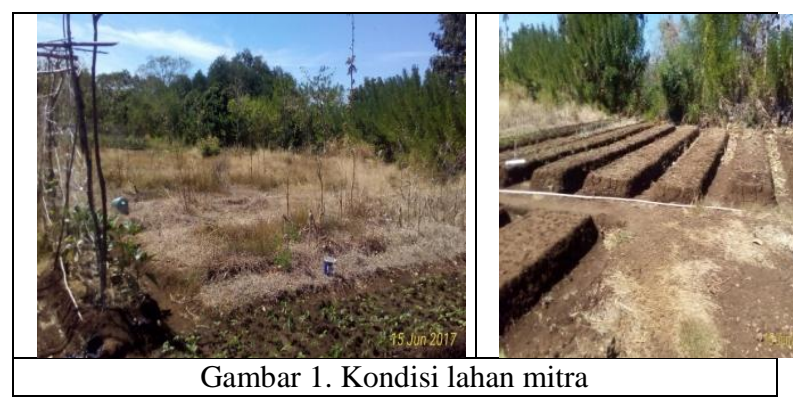

Untuk efisiensi penggunaan air pada lahan kering maka petani perlu mengetahui kebutuhan air tanaman semusim yang di tanam. Kurnia, 2004. mengatakan bahwa Untuk mengetahui jumlah air yang perlu disediakan untuk mengairi lahan pertanian, diperlukan informasi atau data kebutuhan air tanaman yang bergantung kepada jenis dan umur tanaman, waktu atau periode pertanaman, sifat fisik tanah, teknik pemberian air, jarak sumber air dan luas lahan yang akan di airi.

Sumber air untuk usaha pertanian mitra 1 yaitu dari sumber air dari mata air Baumata yang mengalir ke lahan seminggu sekali dan di tampung dalam terpal tampungan, dan dialirkan melalui saluran non teknis yang di buat sendiri untuk masuk mengenangi bedengan-bedengan tanaman (sistem leb). Jarak dari sumber air $\pm 2 \mathrm{~km}$ yang akan sampai ke lahan kira-kira satu jam setelah pintu saluran di buka. Sedangkan sumber air untuk mitra 2 yaitu dari air tangki yang di tampung dalam fiber maupun terpal tampungan air seperti terlihat pada Gambar 2.

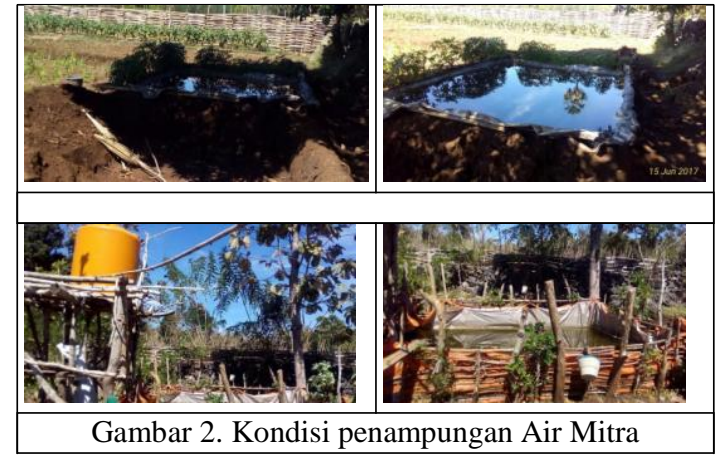

Penerapan teknologi hemat air perlu dilakukan pada kondisi lahan kering seperti ini. Teknologi hemat air yang dapat diterapkan berupa teknologi mulsa berupa mulsa plastic hitam perak dan mulsa organic berupa jerami padi dan teknologi irigasi tetes/drip irigasi dan kombinasi keduanya. Manfaat mulsa bagi tanaman adalah untuk mencegah pertumbuhan gulma, menjaga kelembaban tanah, menjaga struktur tanah, mencegah erosi permukaan tanah serta meminimalisir hama dan penyakit sedangkan manfaat drip irigasi atau irigasi tetes yaitu meningkatkan nilai guna air,meningkatkan pertumbuhan tanaman dan hasil, meningkatkan efisiensi dan efektifitas pemberian pupuk, menekan resiko penumpukan garam, menekan resiko penumpukan garam, menekan pertumbuhan gulma, menghemat tenaga kerja (

Mulsa plastik hitam perak sudah di gunakan kedua mitra namun masih sedikit karena kendala modal.

Menurut Mitra 1 dan 2, bahwa dalam mengusahakan tanaman sayuran tersebut mereka mendapat keuntungan berdasarkan hitungan umum saja. Pencatatan usaha tani tidak lengkap dilakukan dalam arti bahwa Mitra 1 dan 2 mencatat saprodi yang di adakan/ di beli namun tidak mencatat semua kegiatan usahatani termasuk produksi dan hasil penjualnnya.

\section{PERMASALAHAN MITRA}

Permasalahan mitra adalah sebagai berikut :Usaha tani tanaman semusim mengalami kendala kekurangan air.

a. Petani terbatas dalam menentukan tanaman semusim yang akan di budidayakan

b. Belum berkembangnya teknologi hemat air di tingkat petani karena keterbatasan pengetahuan dan modal.

c. Mitra masih terbatas dalam pencatatan usaha tani nya sehingga analisis usaha tidak dilakukan dengan baik dan pasti.

\section{METODE PELAKSANAAN}

Agar program kemitraan masyarakat ini dapat mencapai tujuan maka partisipasi mitra sangat diperlukan. Kegiatan pengabdian ini dilakukan selama tahun 2018 menggunakan metode ceramah (preaching method), metode diskusi (discussion method), on farm method (penerapan langsung di lahan petani), pendampingan, monitoring dan evaluasi pelaksanaan kegiatan.

Tahapan kegiatan meliputi : sosialisasi kegiatan, persiapan lahan dan persiapan teknis untuk menerapkan teknologi mulsa plastic hitam perak serta irigasi tetes/drip irigasi, serta pendampingan budidaya tanaman semusim berupa tanaman melon, kacang panjang, kacang buncis, cabai dan sawi pada demplot petani. 


\section{HASIL KEGIATAN DAN PEMBAHASAN}

Kegiatan kemitraan masyarakat ini menghasilkan :

1. Bak Penampung Air dan saluran irigasi

Untuk menunjang kegiatan budidaya tanaman maka pada perlu dibangun di salah satu mitra berupa bak penampungan air. Bak penampungan air dengan ukuran $6 \times 2 \times 1,5 \mathrm{~m}$ tersebut sudah mulai di bangun mitra, dan dilanjutkan dengan pendanaan dari program pengabdian. Dengan adanya bak air ini mitra memiliki bak tampungan air permanen yang dapat menampung air seminggu sekali sesuai jadwal pembagian air pada daerah tersebut. Mitra merasa terbantu dengan adanya bak air yang dilengkapi dengan dynamo air untuk menaikkan air ke tampungan fiber dan selanjutnya di alirkan ke tanaman menggunakan pipa pvc yang telah dirancang untuk irigasi.

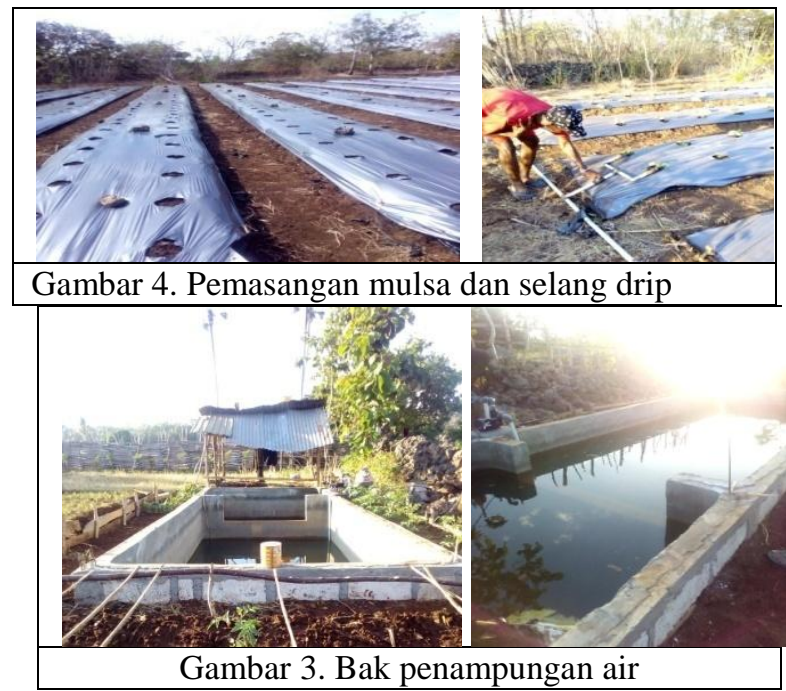

2. Pemasangan instalasi perpipaan dan selang drip untuk budidaya tanaman

Untuk mengalirkan air dari bak tampungan atau sumur bor (pada salah satu mitra) maka air dialirkan ke tampungan fiber yang letaknya lebih tinggi sehingga air dapat dialirkan dengan cara gravitasi melalui perpipaan yang di instalasi ke bedengan. Selang drip untuk irigasi digunakan untuk mengairi air dalam bedengan yang sudah di beri mulsa plastic hitam perak. Budidaya tanaman yang menggunakan teknologi pemulsaan dan irigasi tetes yaitu budidaya melon, buncis, cabai dan kacang panjang. Budidaya tanaman menggunakan irigasi tetes dimaksud untuk menghemat air karena lubang-lubang air dari selang drip hanya di buat pada lubang-lubang tanam sehingga penggunaan air lebih hemat atau efisien, serta waktu yang digunakan petani untuk mengairi tanaman lebih efisien. Respon petani terhadap kegiatan ini yaitu petani merespon baik karena hasi dari kegiatan ini dapat membantu mereka dalam kegiatan budidaya pada tahun-tahun berikutnya.

Dampak dari kegiatan ini adalah petani lebih efisien dalam menggunakan tenaga dan waktu. Pipa dilengkapi dengan stop kran yang dapat di buka dan di tutup sesuai keperluan penggunaan air, petani cuman mengontrol keluarnya air pada selang-selang drip.

\section{Penerapan mulsa dan irigasi drip}

Mulsa yang digunakan dalam kegiatan ini berupa, berupa mulsa plastic hitam perak. Manfaat penggunaan mulsa yaitu mulsa mengurangi penguapan sehingga air lebih efisien digunakan tanaman.

Mulsa dapat digunakan sendiri, juga dapat dikombinasikan dengan selang drip. Kombinasi teknologi mulsa dan irigasi drip dapat dilakukan dengan tujuan menghemat air dan menekan pertumbuhan gulma dan penguapan yang tinggi serta efisiensi waktu dan tenaga kerja untuk mengairi tanaman.

Penggunaan mulsa pada tanaman budidaya dapat dilihat pada gambar 4 .

\section{Kegiatan Penyuluhan}

Selain kegiatan on farm untuk budidaya tanaman semusim yang dilakukan oleh tim pengabdian (Ir. Maria Kalara Salli,MP dan M. Basri,SP.M.Si) juga kegiatan penyuluhan dan praktek pencatatan usaha tani dan pembukuan sederhana bagi petani mitra (Gambar 5).

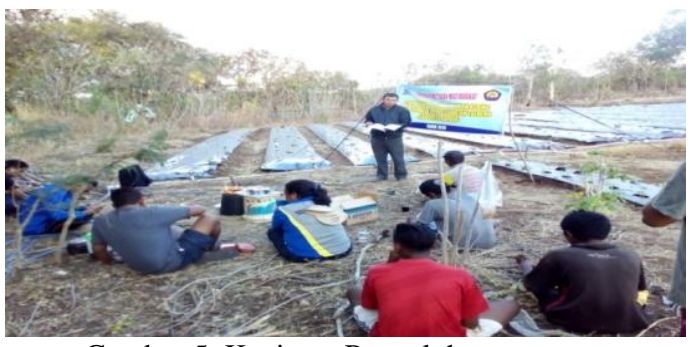

Gambar 5. Kegiatan Penyuluhan

\section{Budidaya Tanaman}

Kegiatan budidaya tanaman langsung dilakukan pada lahan petani dengan membuat demplot. Tanaman semusim yang di budidayakan berupa tanaman melon, cabai, sawi kacang panjang dan buncis (Gambar

$6)$. 


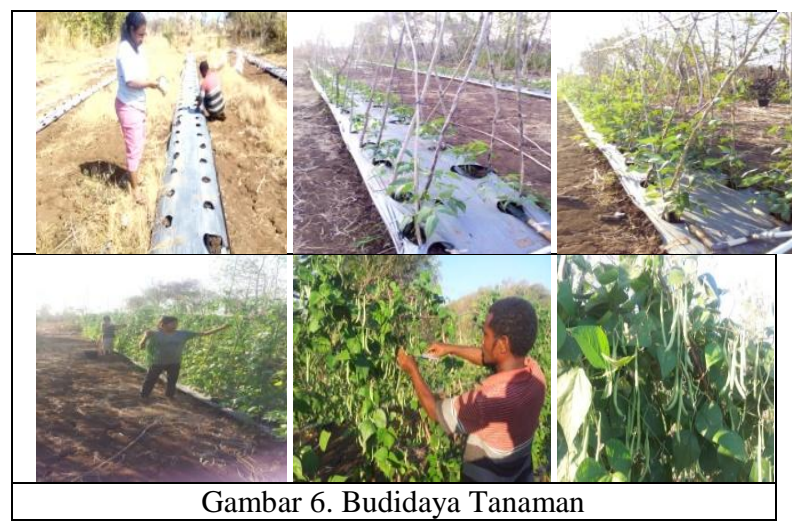

Di bandingkan beberapa tanaman diatas, luas lahan untuk pertanaman melon lebih luas, 2 are, dengan jumlah bedengan 13 bedengan yang berukuran $1 \mathrm{~m} \mathrm{x}$ $15 \mathrm{~m}$ untuk setiap bedengan. Bibit melon yang di tanam berjunlah 750 pohon, setiap pohon dipelihara 2 buah sehingga total buah berjumlah 1500 buah. Jika harga melon Rp.5000 - Rp.10.000 perbuah maka diprediksi petani akan mendapat pendapatan sejumlah Rp. 7.500.000 - Rp.10.000. Jumlah bedengan kacang panjang adalah 2 bedengan dengan ukuran bedeng 1 $\mathrm{m} \times 15 \mathrm{~m}$ dan kacang buncis sebanyak 6 bedengan dengan ukuran bedengan juga $1 \mathrm{~m}$ x 15 meter untuk setiap bedengnya. Hasil penjualan kacang panjang dan kacang buncis sebanyak tiga kali panen diperincikan sebagai berikut : kacang panjang Rp.150.000, kacang buncis Rp. 100.000. sementara Kacang panjang dan kacang buncis masih beberapa kali di panen. Tanaman melon di tanam lebih banyak dengan tujuan agar lebih memantapkan ketrampilan petani untuk membudidayakan tanaman melon sebab pada tahun sebelumnya tanaman melon hasilnya tidak memuaskan karena terserang penyakit.

Kegiatan budidaya melon dapat dilihat pada gambar berikut ini :

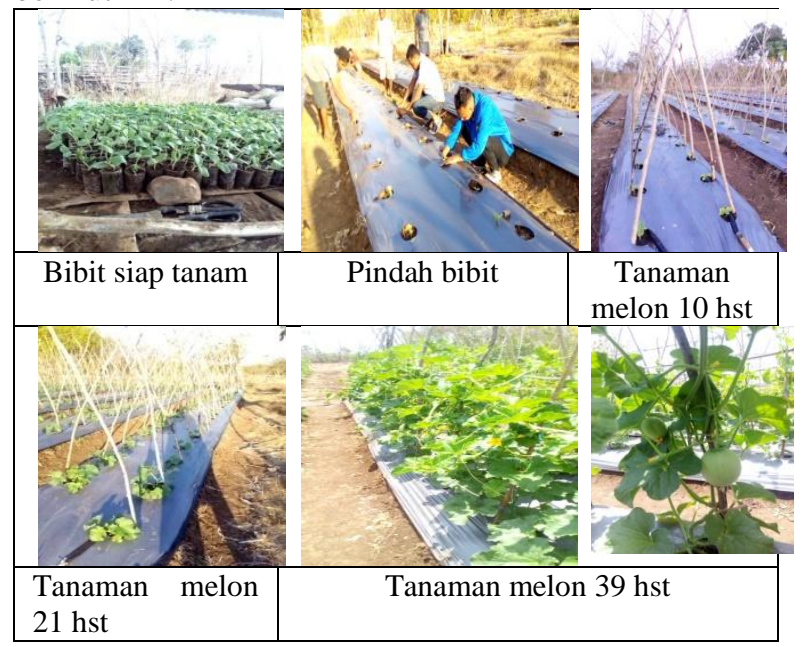

Partisipasi mitra dalam kegiatan pengabdian ini sangat baik, ditunjukkan dengan penataan kebun mitra menjadi lebih baik, tersedianya bak tampungan air, instalasi perpipaan dan selang drip terpasang dan kegiatan budidaya tanaman dapat menghasilkan hasil panen berupa melon, kacang panjang dan kacang buncis.

\section{KESIMPULAN}

Dari pelaksanaan PKM ini dapat disimpulkan bahwa :

1. Kegiatan PKM dapat terlaksana dengan baik, ditunjukkan dengan partisipasi mitra yang tinggi dan budidaya tanaman semusim berhasil dilakukan mitra.

2. Kegitan PKM ini dapat menyelesaikan permasalahan mitra yaitu mitra dapat menyelesaikan permasalahan kekurangan air yaitu dengan teknologi hemat air berupa pemulsaan dan irigasi drip, sehingga lebih banyak lahan yang tertanami, mitra dapat meningkatkan pengetahuan dan ketrampilan dalam budidaya tanaman semusim, dan mitra dapat melakukan pencatatan usahataninya dengan baik.

3. Kegiatan PKM ini sangat bermanfaat bagi mitra, selain meningkatkan keterampilan mitra juga sebagai sumber pendapatan dan kesejahteraan mitra untuk saat ini dan tahun-tahun yang akan datang.

\section{UCAPAN TERIMA KASIH}

Terimakasih kepada Direktorat Riset dan Pengabdian Masyarakat (DRPM) Dikti, Kementrian Riset, Teknologi dan Pendidikan Tinggi yang telah mendanai kegiatan PKM Petani Tanaman Semusim Lahan Kering Di Desa Baumata Timur Kecamatan Taebenu Kabupaten Kupang Tahun 2018.

\section{DAFTAR PUSTAKA}

[1] Anonymous, 2017. Tumbuhan Semusim. id.wikipedia.org/wiki/Tumbuhan_ semusim. Diakses 10 Juni 2017.

[2] Kurnia, U. 2004. Prospek pengairan pertanian tanaman semusim lahan kering. Jurnal Litbang Pertanian 23 (4). Diakses tanggal 2 Juni 2017

[3] Litjang,I,K, Kedang, A. K, De Rosari, B. dan Gunarto,2003. Pengembangan teknologi menunjang sistem usaha tani lahan kering di Kabupaten Ende. Balai Teknologi Pertanian, NTT.

[4] Mahfud,Moh. Cholid, 2012. Teknologi dan strategi pengendalian penyakit karat daun untuk meningkatkan produksi kopi nasional. Jurnal Pengembangan Inovasi Pertanian, 5 (1) 2012 : 44-57

[5] Sukri, M.Z. and Suhermiatien, T., 2016. IBM KELOMPOK TANI PADI RAKYAT (PENERAPAN VARIETAS UNGGUL HIBRIDA BARU DAN TEKNIK JAJAR LEGOWO). J-Dinamika, 1(2). 